\section{C SUSTAINABILITY REPORTING: RAISING THE BAR FOR SAFETY AND HEALTH MANAGEMENT}

WGPerry. U.S. Occupational Safety and Health Administration, Washington, DC, USA

\subsection{6/oemed-2018-ICOHabstracts. 197}

Sustainability reporting has emerged as a key driver for businesses to set ambitious goals, display leadership, innovate, and continuously improve their practices in ways that go beyond compliance with existing regulations. While a safety and health management program that prevents worker injuries and illnesses is a logical component of an organisation's sustainability efforts, these programs have not been a focus of reporting practices to date. Where occupational safety and health has been included in sustainability reports, such reporting has emphasised quantitative indicators such as total and lost-time injury rate histories; little information has typically been provided on other important indicators of performance such as the nature of processes to identify and address safety and health risks, approaches to worker training, practices to encourage reporting of safety and health concerns by employees, and auditing procedures. Updates to the GRI's occupational health and safety disclosures, which shift the focus to qualitative and descriptive approaches for evaluating whether systems are in place to effectively and proactively manage worker safety and health, help set the stage for improved worker protection. Although these disclosures provide a much improved framework for enterprises to provide information to stakeholders on efforts to mitigate workplace risks, they can also serve as a useful model for corporate managers and safety and health professionals to evaluate the strength of their safety and health management program even where enterprises do not engage in public sustainability reporting. Developing a safety and health program or enhancing an existing one based on such a framework can help all organisations better protect workers and improve business performance.

\section{4d IMPROVING HEALTH AND WELLBEING IN THE WORKPLACE: ROLE OF SUSTAINABILITY REPORTING}

HJ Schilthuis. Heineken International, Amsterdam, The Netherlands

\subsection{6/oemed-2018-ICOHabstracts. 198}

The importance of health and wellbeing is increasing, due to ageing workforce, increasing costs of health care and expectations from younger workers. Heineken is a global company operating in many different environments in developed and developing countries. To make it possible to operate sustainably in these different places, attention to the health of the workforce is important. Occupational health is often determined more by local legislation than by the company from a Global perspective, however more and more we see a call for the company to act on the health and wellness of the workforce. At the very minimum, workers who want to be able to live a healthy life, have to be able to do so in the workplace, and the company has to facilitate this. Many of our local operating companies do more than that and provide health care for their employees as well as wellness programs to help employees stay healthy and fit. From a global perspective, our role is to help to set some standards, ensuring that the interventions chosen are based on evidence, and provide a well balanced set of interventions ensuring both the environment of the worker as well as the behaviour are addressed and that all major relevant health issues are taken into account. We ensure that our operating companies adhere to standards on HIV care, basic health care and emergency care in those countries where this is not sufficiently provided by the health care system. The GRI reporting standard on occupational health and safety will help to set the minimum standard for the health and wellness we are doing, but also get some recognition for the work that is being performed and that is to a certain extent reflected in our sustainability reports, but so far not yet in a comparable way.

\section{A RAPID FIRE INTERACTIVE SESSION: CASE STUDIES LINKING COMMUNICATION SCIENCE WITH GOOD PRACTICE}

Max R Lum*. National Institute for Occupational Safety and Health, Washington, D.C., USA

\subsection{6/oemed-2018-ICOHabstracts. 199}

Aim of the special session This session will feature brief case study type presentations providing examples of how good communication practice was used to address a communication problem or integrated into a strategy. Presenters will be given only 7-9 $\min$ to present their case. Case study topics run the gamut from policy issues, campaign practices, new tools, partner engagement, dissemination strategies, social media, video usage, search engine optimisation, metrics, app. development, and listening strategies. The interaction of the audience will be stimulated by questions posed by the presenter.

${ }^{1}$ Robin Nicholas, ${ }^{2}$ Sture Bye, ${ }^{3}$ Chucri Kardous, ${ }^{4}$ Bruce Lippy, ${ }^{5}$ Dietmar Elsler, ${ }^{6}$ Thais Morata, ${ }^{7}$ Sven Timm, ${ }^{8}$ Sara Rouhi, ${ }^{9}$ Steven Horvath, ${ }^{10}$ Mathew Holder, ${ }^{11}$ Stephane Vaxelaire, ${ }^{12}$ Max Lum

${ }^{1}$ Robin Nicholas Communications, Santa Fe, NM, United States

${ }^{2}$ National Institute of Occupational Health (STAMI), Oslo, Norway

${ }^{3}$ National Institute for Occupational Safety and Health (NIOSH), Cincinnati, Ohio, United States

${ }^{4}$ The Centre for Construction Research and Training (CPWR), Silver Spring, MD, United States

${ }^{5}$ European Agency for Safety and Health at Work, (EUOSHA), Bilbao, Spain

${ }^{6} 1$ National Institute for Occupational Safety and Health, (NIOSH) Cincinnati, United States

${ }^{7}$ German Social Accident Insurance (DGUV), Sankt Augustin, Germany

${ }^{8}$ Itmetric.com, London, United Kingdom.

${ }^{9}$ Radiation Safety Institute of Canada, Toronto, Canada

${ }^{10}$ British Safety Council (BSC), London, UK

${ }^{11}$ French Ministry of Agriculture, Paris, France

${ }^{12}$ National Institute for Occupational Safety and Health (NIOSH), Washington, D.C. United States

\section{2a 39 JOBS. LIFE, WORK AND THE MANY LESSONS OF LISTENING AND TALKING ALONG THE WAY}

R Nicholas. Robin Nicholas Communications, Santa Fe, NM, USA

10.1136/oemed-2018-ICOHabstracts.200 